\title{
Multiple Cross Displacement Amplification-a more applicable technique in detecting Pseudomonas Aeruginosa of Ventilator-associated Pneumonia ( VAP)
}

Juxiang Wang

xiamen Cardiovascular Hospital, Xiamen University

Huimin Chen

the third hospital of xiamen

Xiaomin Lin

Xiamen Branch, Zhongshan Hospital, Fudan Unversity

Chengyi Ji

the third hospital of Xiamen

Bin Chen ( $\nabla$ drchenbin@126.com )

Xiamen Port Clinic of Xiamen Customs https://orcid.org/0000-0002-3152-4021

\section{Research}

Keywords: Pseudomonas aeruginosa, multiple cross displacement amplification, ventilated-associated pneumonia, bronchoalveolar lavage fluid, Limit of Detection

Posted Date: May 26th, 2020

DOI: https://doi.org/10.21203/rs.2.22930/v3

License: (c) (i) This work is licensed under a Creative Commons Attribution 4.0 International License.

Read Full License

Version of Record: A version of this preprint was published at Critical Care on June 8th, 2020. See the published version at https://doi.org/10.1186/s13054-020-03003-4. 


\section{Abstract}

Background: Early and rapid identification of Pseudomonas aeruginosa (P. aeruginosa) in patients with suspected ventilator-associated pneumonia (VAP) provides theoretical clinical advantages in therapeutic optimization strategies.

Methods: The P. aeruginosa-multiple cross displacement amplification (PA-MCDA) assay was conducted at an isothermal temperature during the amplification stage, and products were visually detected by color changes. The entire process was completed within $1 \mathrm{~h}$. A total of 77 strains, including P. aeruginosa species and various other species of non-P. aeruginosa were used to evaluate PA-MCDA assays. Bronchoalveolar lavage fluid (BALF) of suspected VAP patients were examined by the MCDA assay.

Results: The MCDA assay exhibited a 100 percent analytical specificity in detecting PA from all 77 strains, and the limit of detection were as low as $100 \mathrm{fg}$ DNA per reaction. A temperature of $65^{\circ} \mathrm{C}$ was recommended as standard during the amplification stage. The agreement between PA-MCDA and bacteria culture was $91.18 \%(K=0.787 ; p=0.000)$ in identification of $P$. aeruginosa in BALF from suspected VAP. The PA-MCDA assay showed values of $92.31 \%, 90.78 \%, 77.41 \%$ and $97.18 \%$ for sensitivity, specificity, positive predictive value and negative predictive value, respectively. PA-MCDA had higher detective rate of P. aeruginosa than bacteria culture in patients with antipseudomonal therapy.

Conclusions: The instrument-free platform of the MCDA assay makes it a simple, rapid and applicable procedure for "on-site" diagnosis and point-of-care testing for the presence of P. aeruginosa without the need for specific bacterial culture.

\section{Background}

Ventilator-associated pneumonia (VAP) develops in intensive care unit (ICU) patients that have been mechanically ventilated for at least $48 \mathrm{~h}[1]$. The infection rate was related to disease severity and the degree of organ failure[2]. Further, the EU-VAP study[3]identified that the overall incidence of VAP was 18.3 episodes per 1000 ventilator-days. Moreover, Pseudomonas aeruginosa ( $P$. aeruginosa) and Staphylococcus aureus were the most frequently isolated pathogens in patients with VAP. In a multicenter study[4], P. aeruginosa, Acinetobacter baumannii, and Klebsiella pneumonia were found the most frequent bacteria $(97 / 212,45.8 \%)$ in VAP patients. In addition, VAP induced a more prolonged need for mechanical ventilation, number of ICU stays and hospitalization, far worse outcomes, and increased associated healthcare costs $[5,6]$.

Rapid completion of antibiotic administration might decrease the incidence of subsequent organ dysfunction and could be associated with a lower risk-adjusted in-hospital mortality rate [7]. The conventional detection of $P$. aeruginosa in the clinical setting was generally achieved by growing the target pathogen on agar plate surfaces and cultures[8]. Although the culture-based technique is reliable, 
the time required for conducting it is at least for a period of $48 \mathrm{~h}$ [9]. Furthermore, published guidelines recommended an initial empiric combinatorial coverage with antibiotics targeted to Gram-negative and Gram-positive bacteria Methicillin-resisitant Staphylococcus aureus (MRSA) in the setting of high-risk VAP patients prior to obtaining culture results[1]. Inappropriate initial anti-microbial therapy and antibiotic exposure attributed to antibiotic-resistance[10,11]was associated with increased in-hospital mortality rates [12]. Rapid and accurate identification of the suspected pathogens was thus warranted to provide the potential to maximize administration of appropriate specific antibiotic and possibly avoid a need for empiric broad-spectrum antibiotic therapy. Rapid excluding some specific and common pathogens would be possible to avoid unnecessary antibiotic exposure and minimize some undesirable consequences[13].

More recently, multiple cross displacement amplification (MCDA, Chinese IP Office Patent Application CN201510280765.X), auto-cycling, and strand displacement DNA synthesis was devised and validated as a possible replacement for PCR-based assays and applicability in the detection of specific nucleic-acid sequences $[14,15]$. The assay employed an isothermal temperature during amplification, and the products were visually detected by color changes. The entire process is completed in $1 \mathrm{~h}$ and benefits from being an instrument-free, simple and practical procedure for 'on-site' diagnosis and point-of-care testing. The current study is the first to report application of the novel MCDA assay to rapidly detect the target pathogen, $P$. aeruginosa.

\section{Methods}

\section{PA-MCDA assay primer design}

Based on the mechanism of MCDA, a set of MCDA primers used for $P$. aeruginosa. detection was designed that targeted the oprL gene, which encodes L-lipoprotein. The details of MCDA primers used in the report are shown in Figure 1 and Table 2 . The primers were commercially synthesized and purified by Tsingke (Beijing, China).

\section{PAMCDA reactions}

MCDA reactions were performed in a one-step reaction in a $25 \mu \mathrm{l}$ mixture containing $12.5 \mu \mathrm{l} 2 \times$ the supplied buffer (BeiJing- Hai Tai Zheng Yuan Technology Co., Ltd.), $0.1 \mu$ each of the displacement primers $\mathrm{F} 1$ and $\mathrm{F} 2,0.2 \mu \mathrm{l}$ each of the amplification primers $\mathrm{C} 1, \mathrm{C} 2, \mathrm{R} 1, \mathrm{R} 2, \mathrm{D} 1$ and $\mathrm{D} 2,0.4 \mu \mathrm{l}$ each of the cross primers $\mathrm{CP} 1$ and $\mathrm{CP} 2,1 \mu \mathrm{l}(8 \mathrm{U})$ of Bst 2.0 DNA polymerase, $1 \mu$ l of the DNA template and $0.8 \mu \mathrm{l}$ of the colorimetric indicator. Moreover, negative control mixtures contained $10 \mathrm{ng}$ of the Staphylococcus aureus and Klebsiella pneumoniae genomic templates, and blank control mixtures contained $1 \mu \mathrm{l}$ of double distilled water (DW). To evaluate the feasibility of the MCDA primer set that was designed to detect $P$. aeruginosa, we initially conducted the MCDA reactions at $63^{\circ} \mathrm{C}$ for $45 \mathrm{~min}$ and terminated the 
MCDA reaction by heating at $85^{\circ} \mathrm{C}$ for $5 \mathrm{~min}$. Then, the optimal amplification temperature of the MCDA primer set was examined at fixed temperatures from $59^{\circ} \mathrm{C}-68^{\circ} \mathrm{C}$ at steps of $1{ }^{\circ} \mathrm{C}$ intervals. In particular, MCDA products were detected using a colorimetric indicator and agarose gel electrophoresis.

\section{Bacterial strains and genomic template preparation}

A total of 124 bacterial strains and 14 fungi of positive culture were isolated in the clinical microorganism laboratory of the Third Hospital of Xiamen from 26th June to 26th July, 2017 The bacterial strains list of standard culture is detailed in Additional file 1. The positive bacterial strains including 6/124(4.84\%) polymicrobial growth and 32/124(22.81\%) Multidrug-Resistant (MDR) strains were isolated from 118 clinical samples in which the tracheal aspirate and BALF in 38 cases, the secretion and drainage in 33 cases, the blood in 16 cases, urine, faeces, catheter and other samples in 31 cases. We chose top 13 bacteria strains, 77 samples to design the PA-MCDA reactions (Table 3). The bacteria strains identified by conventional cultivation method囚automatic bacterial identification system (VITEK 2هBio-Merieux, France) were stored in a $15 \%(\mathrm{w} / \mathrm{v})$ glycerol broth at $-70^{\circ} \mathrm{C}$. After refreshing the culture three times on a nutrient agar plate at $37^{\circ} \mathrm{C}$, the genomic templates were then extracted from all cultured strains using DNA extraction kits Qiagen Co.,Ltd. Beijing, China), and subsequently tested with an ultraviolet spectrophotometer and stored under $-20^{\circ} \mathrm{C}$ before use.

\section{Specificity of the PA-MCDA assay}

To evaluate the analytical specificity of the PA-MCDA assay, MCDA reactions were conducted under conditions that were described above with the $77 P$. aeruginosa and non- $P$. aeruginosa pure genomic templates that were derived from all pure bacterial strains.

\section{Sensitivity of the PAMCDA assay}

The genomic templates of $P$. aeruginosa were serially diluted (10 ng, $1 \mathrm{ng}, 100 \mathrm{pg}, 10 \mathrm{pg}, 1 \mathrm{pg}, 100 \mathrm{fg}, 10$ $\mathrm{fg}$ and $1 \mathrm{fg}$ per microliter) with the intent of verifying the limit of detection (LoD), and $1 \mu$ l of each serial dilution was then added to the MCDA reaction mixtures. The LoD of the MCDA assay was confirmed by the genomic DNA concentration of the template. MCDA results were detected using a colorimetric indicator, malachite green, MG (BeiJing- Hai Tai Zheng Yuan Technology Co., Ltd.) and 2.5\% agarose gel electrophoresis.

\section{Verification of the PA-MCDA assay}


This study was conducted in the 30-bed ICU of The Third Hospital of Xiamen in Fujian province, which is a 1200-bed hospital in China. A total of 102 patients enrolled in this study who were suspected VAP from 1st January 2018 to 14th March 2020. Patients satisfied two or more of the following criteria: fever > $38.5^{\circ} \mathrm{C}$, leukocytosis $>10^{9} / \mathrm{L}$ or leukopenia $<4 \times 10^{8} / \mathrm{L}$, purulent tracheobronchial secretions, and a new or persistent infiltrate on chest radiography. The following data were recorded: demographic characteristics, indication(s) for ICU admission, prior antimicrobial therapy within 2 months before VAP, duration of mechanical ventilation before VAP, Clinical pulmonary infection score (CPIS[16]) including temperature, blood leukocytes, tracheal secretions, oxygenation and pulmonary radiography, usual biochemical and hematological tests.

The BALF were abstracted in one bottle, following which, one half $(5 \mathrm{ml})$ processed for standard culture by the clinical microorganism laboratory of the Third Hospital of Xiamen and the other $5 \mathrm{ml}$ stored at $-70^{\circ} \mathrm{C}$ until the time of DNA extraction. BALF was plated on chocolate, sheep blood, and MacConkey agar plates and incubated for 48-72 $\mathrm{h}$ according to routine clinical protocol. The DNA extraction from BALF method was described before. In this procedure, $1 \mu \mathrm{l}$ of the extracted DNA template of the BALF specimen was added to the PA-MCDA assay and the reactions were performed at an optimal amplification temperature for $45 \mathrm{~min}$. The products were detected by a color change and compared to the results of a standard clinical culture, which was blinded to the research investigators. This study was approved by the local ethics committee of the Third Hospital of Xiamen, and performed according to the ethical standards of the latest revision of the Declaration of Helsinki. Written and informed consent was obtained from family members or the appropriate responsible parties.

\section{Statistical analysis}

Continuous variables of patients' characteristics were reported as the means \pm standard deviations (SD) or the medians (interquartile ranges (IQR)), and categorical variables were reported as numbers (\%). The accuracy of the PA-MCDA assay was compared with the microbiological culture in a cross-sectional analysis. P value $<0.05$ was considered significant. Statistical analysis was performed using SPSS version 20.0 for Windows (SPSS Inc., Chicago, IL, USA).

\section{Results}

\section{Successful establishment of the PA-MCDA assay}

To verify the feasibility of $P A-M C D A$ primers, the MCDA reactions were initially carried out in the presence or absence of genomic DNA templates within $45 \mathrm{~min}$ at a constant temperature of $63^{\circ} \mathrm{C}[14]$. A color shift of positive amplification in PA-MCDA tubes was directly observed to change from one of colorless to one of green, while the negative control tube remained colorless by the naked eye (Fig. 2A). The positive MCDA products were seen as ladder-like patterned bands on ethidium bromide-stained $2.5 \%$ agarose gels 
that were resolved by electrophoresis; however, these were not seen in the Staphylococcus aureus, Klebsiella pneumonia or blank control (Fig.2B). Hence, the designed MCDA primer was a good candidate to establish the MCDA methodology for detecting $P$. aeruginosa.

\section{Optimizing the temperature for the PA-MCDA assay}

To confirm the optimal reaction temperature for the PA-MCDA assay, the $P$. aeruginosa strain was used as a positive control at a concentration of $1 \mathrm{ng}$ per tube and the MCDA amplifications were monitored by a real-time turbidity technique. Performing the $P A-M C D A$ assay at temperatures that ranged from $59^{\circ} \mathrm{C}$ to $67^{\circ} \mathrm{C}$ at $1^{\circ} \mathrm{C}$ increments, verified that $65^{\circ} \mathrm{C}$ was an optimal temperature for amplification - with a faster amplification procedure obtained from assay temperatures of $65^{\circ} \mathrm{C}$ (Fig. 3 ).

\section{Specificity and sensitivity for $P$. aeruginosa detection by MCDA assays}

When genomic templates were used in MCDA assays, only the genomic DNAs that were isolated from the $P$. aeruginosa strains (tubes 1 to 17) generated positive results. Genomic templates from all non- $P$. aeruginosa strains (1tubes 8 to 34 ) did not provide production of detectable amplification products (Fig. 4). The color change was observed in positive MCDA tubes (tubes 1 to 17), and a ladder-like pattern was seen on an ethidium bromide-stained $2.5 \%$ agarose gel via electrophoresis resolution. These were not seen in negative tubes (Fig. 4).

Serial dilution of the $P$. aeruginosa genomic DNA (10 ng, $1 \mathrm{ng}, 100 \mathrm{pg}, 10 \mathrm{pg}, 1 \mathrm{pg}, 100 \mathrm{fg}, 10 \mathrm{fg}$ and $1 \mathrm{fg}$ per microliter) were used in MCDA assays. Fig. 5A and 5B). It indicated that the LoD, and the sensitivity of the PA-MCDA assay was $100 \mathrm{fg}$ genomic templates per reaction.

\section{Application of PA-MCDA to clinical samples}

The MCDA assay was used to examine 102 BALF from patients who were suspected of presenting with VAP. Demographic and clinical characteristics of our patients are shown in Table 1. The median duration of mechanical ventilation was 7 days (IQR 4.00-32.50) before suspected VAP onset and 97 patients had received antibiotics within two months before suspected VAP. The clinical diagnosis of VAP was given by 
physician judgment with respect to particular patients or special clinical situations combination with culture results. A total of 94 positive bacteria results were detected by conventional culture in 82/102(80.39\%) BALFs in which Polymicrobial growth was 12/102(11.76\%) and Polymicrobial included P. aeruginosa were $4 / 102(3.92 \%)$. Bacterial strains list of BALF by standard culture is detailed in Additional file 2. After extracting DNA from these BALF specimens and adding $1 \mu$ l of the DNA template to the PA-MCDA assay, the reactions were carried out at $65^{\circ} \mathrm{C}$ for $45 \mathrm{~min}$ and the results were compared to those of the standard culture. The $P$. aeruginosa was detected in 26 samples by microbiological culture and in 31 samples by PA-MCDA. Two methods unanimously detected $24 P$. aeruginosa strains while the MCDA detected $7 P$. aeruginosa strains in culture negative patients who received antipseudomonal therapy. The positive results of PA-MCDA and microbiological culture were $24 / 76(31.58 \%)$ and $17 / 76(22.37 \%)$ respectively in 76 patients who had received antipseudomonal therapy. In the crosssectional analysis, the agreement between the tests was $91.18 \%(\mathrm{k}=0.787 ; p=0.000)$, likelihood ratio positive was 10.02 and likelihood ratio negative was 0.08 .The PA-MCDA assay showed values of $92.31 \%, 90.78 \%, 77.41 \%$ and $97.18 \%$ for sensitivity, specificity, positive predictive value and negative predictive value, respectively.

\section{Discussion}

PA-MCDA reaction was performed with a set of 10 oligonucleo tide primers, which specifically recognized 10 distinct sites on the target sequence, wherein the optimal temperature for amplification was $65^{\circ} \mathrm{C}$. In particular, a colorimetric indicator (malachite green, MG) had been applied and the color changed from colorless to a light green color when the reaction was positive. The specificity of the PA-MCDA assay was 100 percent, and the sensitivity achieved a level as low as $100 \mathrm{fg}$ of the template. The entire procedure, including that of specimen processing ( $15 \mathrm{~min})$, the isothermal reaction, and result reporting (45 $\mathrm{min})$, could be completed in approximately $1 \mathrm{~h}$. The agreement between PA-MCDA and bacteria culture was $91.18 \%(\mathrm{~K}=0.787 ; p=0.000)$ in identification of $P$. aeruginosa in BALF from suspected VAP. PA-MCDA had higher detective rate of $P$. aeruginosa than bacteria culture in patients who had received antipseudomonal therapy.

A rapid, simple and accurate detection method of pathogenic microorganisms was necessary for the timely administration of appropriate therapy and arriving at a time to discontinue unnecessary antibiotic(s). Delayed receipt of an appropriate antibiotic(s) was independently associated with poorer clinical and economic outcomes in patients with serious Gram-negative bacterial infections, regardless of any resistance status[9].Molecular diagnostic assays, such as PCR-based methods (e.g., conventional PCR, real-time PCR [17], and PCR-Electro Spray Ionization MS (PCR/ESI-MS)[18], permit more rapid detection of targeted bacterium by nucleic acid amplification, and have been established and applied in the clinic. However, these PCR-based techniques have some shortcomings, which include the following: (i) the instrument used is extremely expensive; (ii) the diagnostic specificity is highly affected by the amplification conditions and the primer design; (iii) use of these techniques indicate that PCR results 
require gel electrophoretic analysis or real-time analytical apparatus. Matrix-assisted laser desorption/ionization time of flight mass spectrometry (MALDI-TOF)[19] consistently decreased the time for successful identification of the pathogenic organism, shorten the period of time for administering an effective and optimal antibiotic and thus arrive at improved patient outcomes. However, it also needs a bacterial culture and expensive instruments.

For diagnosis of VAP, not the standard culture but the MCDA assay are intended to supplant physician judgment respect to particular patients or special clinical situations. The PA-MCDA assay just represents a rapid, sensitive and nearly instrument-free method of $P$. aeruginosa detection. Only a water bath or heat block was needed during the reaction stage and the cost is about $₫ 8$ per sample compared to standard culture is $₫ 10$ per sample. Due to MCDA being able to provide results within only one hour, the clinician can save time to provide targeted therapy for patients, especially in the context of severe sepsis or septic shock patients. The positive test of PA-MCDA means there were $P$. aeruginosa in BALF, an initial narrow antibiotic therapy with antipseudomonal activity should be given in stable patients with suspected VAP in order to provide targeted therapy and reduce antibiotic exposure. The broad-spectrum empiric therapy with antipseudomonal activity needed to given in patients with severe acute respiratory distress syndrome and profound (unstable) septic shock when the PA-MCDA were positive because the high sensitivity for PA-MCDA assays and the polymicrobial growth always existed. The negative test indicated that there were no $P$. aeruginosa growth or the number of $P$. aeruginosa was very below the $10^{4} \mathrm{cfu} / \mathrm{ml}$ in the BALFs as the high sensitivity of PA-MCDA assay[20]. The value was that empiric combination coverage for $P$. aeruginosa might not be necessary and the discontinuation of antibiotic therapy with antipseudomonal activity needed to be considered by clinicians[13]. Although, the bacterium specificMCDA assay cannot differentiate the infection from colonization for it cannot quantitative the bacteria strains of BALF that is the methodology to diagnose VAP, the different time of color change of positive MCDA assay may relate to the amount of DNA templates of bacteria because its reaction products could be detected by real-time fluorescence and less time of positive reactions were produced in more specificDNA templates[20]. Whether a threshold time of color change for MCDA reflects the quantitative or semiquantitative bacterium for clinical application needs a precise design and analysis. The PA-MCDA assay also detected 7 positive $P$. aeruginosa, while standard culture was negative in 76 patients who had received antipseudomonal therapy.The interpretation might suggest the MCDA approach had a higher sensitivity than standard culture[15,21], or that the culture negativity might reflect the presence of active culture inhibitors in the samples[22], or that the $P$. aeruginosa had become non-viable before or even between the standard culture periods since the growth conditions had changed. Clinical factors should also be taken into account because they might alter the decision of whether to withhold or continue antibiotics. The ultimate clinical determination of VAP, pathogens and regarding antibiotics application was made by the physician in the light of each patient's individual circumstances[13]. 
In order to use MCDA method to clinical application, this study also has limitations. The first is the bacterium specific-MCDA assay cannot differentiate the infection from colonization because it cannot provide the results of quantitative bacterium of BALF. A more precise study will be designed recently to explore the relationship between a cutoff time for MCDA color change and the quantitative or semiquantitative bacterium in clinical samples. In addition, whether or not the assay could detect the target pathogen in other specimens such as blood, urine or serous effusion needs further study. Consequently, both the negative and positive results of PA-MCDA cannot rule out the presence of other pathogens, Gram-positive or Gram-negative bacteria or fungi, for polymicrobial growth always existed. MCDA cannot provide precise information to prescribe or withdrew pathogen-specific therapy[23] until more pathogen specific-MCDA and resistance-associated genes be designed[20]. We propose to assign some microorganism-specific MCDA assays and resistance-associated genes (e.g., the $\mathrm{nfxB}$ gene and the blaPER-1 gene) $[18,19,24,25]$ that are aligned to common pathogens in ICU, which would include Staphylococcus. aureus (MRSA)[26] , Acinetobacter baumannii, Escherichia coli, fungal species, and others in one template.

\section{Conclusions}

The PA-MCDA assay for rapid detection of $P$. aeruginosa, which was based on the oprL gene was successfully developed. This approach enabled its reaction products to be identified by the naked eye, and the assay established a high degree of both specificity and sensitivity for target template analysis. The PA-MCDA assay does not only have the benefit of a rapid, reliable and nearly instrument-free procedure, but it can differentiate $P$. aeruginosa from pure strains of bacteria and clinical specimens without the need for time-consuming bacterial culture and its clinical significance needs further establishment.

\section{Declarations}

\section{Acknowledgements}

This study was supported by the Third Hospital of Xiamen Affiliated of Fujian University of Traditional Chinese Medicine. We would also like to express our gratitude to the clinicians and healthcare professionals who helped us in this study.

\section{Funding}

This study was supported by a grant from the Medical Innovation Project of Fujian Province funded by the Xiamen Municipal Health Commission [grant number 2015-CXB-48] 
Availability of data and materials

The dataset analysed during the current study is available from the corresponding author on reasonable request.

\section{Authors' contributions}

The corresponding author (BC) was in charge of study design. The first author (JXW) was responsible for manuscript writing and cooperated with the rest three authors (HMC, XML and CYJ) in clinical research work. JXW was in charge of data collection and experiment, BC was responsible for data analysis. HMC, $\mathrm{XML}$ and CYJ were responsible for sample collection, experiment technical and material support during the study. All authors have read and approved the publication of this manuscript.

\section{Ethics approval and consent to participate}

All procedures in the study were performed in accordance with the ethical standards of the institutional research committee and with the 1964 Declaration of Helsinki and its later amendments or comparable ethical standards. Written and informed consent was obtained from family members or the appropriate responsible parties.

\section{Consent for publication}

Not applicable

\section{Competing interests}

All authors declared that they have no competing interests.

\section{References}

1. Torres A, Niederman MS, Chastre J, Ewig S, Fernandez-Vandellos P, Hanberger H, Kollef M, Li Bassi G, Luna CM, Martin-Loeches I et al: International ERS/ESICM/ESCMID/ALAT guidelines for the management of hospital-acquired pneumonia and ventilator-associated pneumonia. Guidelines for the management of hospital-acquired pneumonia (HAP)/ventilator-associated pneumonia (VAP) of the European Respiratory Society (ERS), European Society of Intensive Care Medicine (ESICM), European Society of Clinical Microbiology and Infectious Diseases (ESCMID) and Asociación Latinoamericana del Tórax (ALAT) 2017, 50(3):1700582. 
2. Vincent JL, Rello J, Marshall J, Silva E, Anzueto A, Martin CD, Moreno R, Lipman J, Gomersall C, Sakr $Y$ et al: International study of the prevalence and outcomes of infection in intensive care units. Jama 2009, 302(21):2323-2329.

3. Koulenti D, Tsigou E, Rello J: Nosocomial pneumonia in 27 ICUs in Europe: perspectives from the EUVAP/CAP study. European journal of clinical microbiology \& infectious diseases : official publication of the European Society of Clinical Microbiology 2017, 36(11):1999-2006.

4. Cisneros JM, Rosso-Fernández CM, Roca-Oporto C, De Pascale G, Jiménez-Jorge S, FernándezHinojosa E, Matthaiou DK, Ramírez P, Díaz-Miguel RO, Estella A et al: Colistin versus meropenem in the empirical treatment of ventilator-associated pneumonia (Magic Bullet study): an investigatordriven, open-label, randomized, noninferiority controlled trial. Critical Care 2019, 23(1):383.

5. Safdar N, Dezfulian C, Collard HR, Saint S: Clinical and economic consequences of ventilatorassociated pneumonia: a systematic review. Crit Care Med 2005, 33(10):2184-2193.

6. Zimlichman E, Henderson D, Tamir O, Franz C, Song P, Yamin CK, Keohane C, Denham CR, Bates DW: Health Care-Associated Infections: A Meta-analysis of Costs and Financial Impact on the US Health Care SystemMeta-analysis of Health Care-Associated InfectionsMeta-analysis of Health CareAssociated Infections. JAMA Internal Medicine 2013, 173(22):2039-2046.

7. Rhodes A, Evans LE, Alhazzani W, Levy MM, Antonelli M, Ferrer R, Kumar A, Sevransky JE, Sprung CL, Nunnally ME et al: Surviving Sepsis Campaign: International Guidelines for Management of Sepsis and Septic Shock: 2016. Intensive care medicine 2017, 43(3):304-377.

8. Jacobs JA, De Brauwer El, Cornelissen El, Drent M: Accuracy and precision of quantitative calibrated loops in transfer of bronchoalveolar lavage fluid. J Clin Microbio/ 2000, 38(6):2117-2121.

9. Bonine NG, Berger A, Altincatal A, Wang R, Bhagnani T, Gillard P, Lodise T: Impact of Delayed Appropriate Antibiotic Therapy on Patient Outcomes by Antibiotic Resistance Status From Serious Gram-negative Bacterial Infections. The American Journal of the Medical Sciences 2019, 357(2):103110.

10. Ong DS, Jongerden IP, Buiting AG, Leverstein-van Hall MA, Speelberg B, Kesecioglu J, Bonten MJ: Antibiotic exposure and resistance development in Pseudomonas aeruginosa and Enterobacter species in intensive care units. Crit Care Med 2011, 39(11):2458-2463.

11. Kollef KE, Schramm GE, Wills AR, Reichley RM, Micek ST, Kollef MH: Predictors of 30-Day Mortality and Hospital Costs in Patients With Ventilator-Associated Pneumonia Attributed to Potentially Antibiotic-Resistant Gram-Negative Bacteria. CHEST 2008, 134(2):281-287.

12. Micek ST, Wunderink RG, Kollef MH, Chen C, Rello J, Chastre J, Antonelli M, Welte T, Clair B, Ostermann $\mathrm{H}$ et al: An international multicenter retrospective study of Pseudomonas aeruginosa nosocomial pneumonia: impact of multidrug resistance. Critical care (London, England) 2015, 19(1):219-227.

13. Kalil AC, Metersky ML, Klompas M, Muscedere J, Sweeney DA, Palmer LB, Napolitano LM, O'Grady NP, Bartlett JG, Carratala J et al: Management of Adults With Hospital-acquired and Ventilatorassociated Pneumonia: 2016 Clinical Practice Guidelines by the Infectious Diseases Society of 
America and the American Thoracic Society. Clinical infectious diseases : an official publication of the Infectious Diseases Society of America 2016, 63(5):e61-e111.

14. Wang Y, Wang Y, Luo L, Liu D, Luo X, Xu Y, Hu S, Niu L, Xu J, Ye C: Rapid and Sensitive Detection of Shigella spp. and Salmonella spp. by Multiple Endonuclease Restriction Real-Time Loop-Mediated Isothermal Amplification Technique. Front Microbiol 2015, 6:1400-1400.

15. Wang Y, Wang Y, Ma A-J, Li D-X, Luo L-J, Liu D-X, Jin D, Liu K, Ye C-Y: Rapid and Sensitive Isothermal Detection of Nucleic-acid Sequence by Multiple Cross Displacement Amplification. Sci Rep 2015, 5:11902-11902.

16. Pugin J, Auckenthaler R, Mili N, Janssens JP, Lew PD, Suter PM: Diagnosis of ventilator-associated pneumonia by bacteriologic analysis of bronchoscopic and nonbronchoscopic "blind" bronchoalveolar lavage fluid. The American review of respiratory disease 1991, 143(5 Pt 1):11211129.

17. Frye AM, Baker CA, Rustvold DL, Heath KA, Hunt J, Leggett JE, Oethinger M: Clinical impact of a realtime PCR assay for rapid identification of staphylococcal bacteremia. J Clin Microbio/ 2012, 50(1):127-133.

18. Bogaerts P, Hamels S, de Mendonca R, Huang T-D, Roisin S, Remacle J, Markine-Goriaynoff N, de Longueville F, Plüster W, Denis 0 et al: Analytical validation of a novel high multiplexing real-time PCR array for the identification of key pathogens causative of bacterial ventilator-associated pneumonia and their associated resistance genes. Journal of Antimicrobial Chemotherapy 2012, 68(2):340-347.

19. Huang AM, Newton D, Kunapuli A, Gandhi TN, Washer LL, Isip J, Collins CD, Nagel JL: Impact of Rapid Organism Identification via Matrix-Assisted Laser Desorption/lonization Time-of-Flight Combined With Antimicrobial Stewardship Team Intervention in Adult Patients With Bacteremia and Candidemia. Clinical Infectious Diseases 2013, 57(9):1237-1245.

20. Wang Y, Wang Y, Zhang L, Liu D, Luo L, Li H, Cao X, Liu K, Xu J, Ye C: Multiplex, Rapid, and Sensitive Isothermal Detection of Nucleic-Acid Sequence by Endonuclease Restriction-Mediated Real-Time Multiple Cross Displacement Amplification. Front Microbiol 2016, 7:753.

21. Kumar A, Ellis P, Arabi Y, Roberts D, Light B, Parrillo JE, Dodek P, Wood G, Kumar A, Simon D et al: Initiation of Inappropriate Antimicrobial Therapy Results in a Fivefold Reduction of Survival in Human Septic Shock. CHEST 2009, 136(5):1237-1248.

22. Dickson RP, Erb-Downward JR, Prescott HC, Martinez FJ, Curtis JL, Lama VN, Huffnagle GB: Analysis of culture-dependent versus culture-independent techniques for identification of bacteria in clinically obtained bronchoalveolar lavage fluid. J Clin Microbio/ 2014, 52(10):3605-3613.

23. Giani T, Arena F, Pollini S, Di Pilato V, D’Andrea MM, Henrici De Angelis L, Bassetti M, Rossolini GM, Group PaW: Italian nationwide survey on Pseudomonas aeruginosa from invasive infections: activity of ceftolozane/tazobactam and comparators, and molecular epidemiology of carbapenemase producers. Journal of Antimicrobial Chemotherapy 2017, 73(3):664-671. 
24. Jenny M, Kingsbury J: Properties and Prevention: A Review of Pseudomonas aeruginosa. J Biol Med Res 2018, 2 (3):8.

25. Evans SR, Tran TTT, Hujer AM, Hill CB, Hujer KM, Mediavilla JR, Manca C, Domitrovic TN, Perez F, Farmer M: Rapid Molecular Diagnostics to Inform Empiric Use of Ceftazidime/Avibactam and Ceftolozane/Tazobactam Against Pseudomonas aeruginosa: PRIMERS IV. Clinical Infectious Diseases 2018.

26. Gong L, Liu E, Che J, Li J, Liu X, Xu H, Liang J: Multiple Cross Displacement Amplification Coupled With Gold Nanoparticles-Based Lateral Flow Biosensor for Detection of the Mobilized Colistin Resistance Gene mcr-1. Front Cell Infect Microbiol 2019, 9:226-226.

\section{Tables}

Table 1. Demographic, clinical and biological characteristics of patients

\begin{tabular}{|c|c|}
\hline Characteristics at ICU admission & Total $\square n=102 \square$ \\
\hline Male sex, n(\%) & 75口73.5\%ם \\
\hline Age(years),median(IQR) & $54.62 \pm 19.59,57 \square 39.75-70.75 \square$ \\
\hline Medical patients, n (\%) & $39 \square 38.2 \% \square$ \\
\hline Surgery patients, n (\%) & $63 \square 61.8 \% \square$ \\
\hline Prior antibiotics in 90 days, $\mathrm{n}(\%)$ & $61059.8 \% \square$ \\
\hline \multicolumn{2}{|l|}{ Characteristics upon VAP onset } \\
\hline ICU stay (days), median(IQR) & $37.87 \pm 80.45,8 \square 4.00-37.75 \square$ \\
\hline Duration of $M V^{\star}$ (days), median(IQR) & $35.42 \pm 80.05,7[4.00-32.50 \square$ \\
\hline Septic shock, n (\%) & $57 \square 55.9 \% \square$ \\
\hline new or persistent infiltrate on chest radiography & $72(70.59 \%)$ \\
\hline CPIS** & $6.59 \pm 1.70,705.00-8.000$ \\
\hline CRP & $84.59 \pm 57.98,69.45(46.00-104.80)$ \\
\hline PCT & $17.34 \pm 24.29,10 \square 2.34-21.30 \square$ \\
\hline \multicolumn{2}{|l|}{ Antibiotics -within 3 days } \\
\hline None & $5 \square 4.9 \% \square$ \\
\hline Monotherapy & $41 \square 40.2 \% \square$ \\
\hline Combination antibiotic therapy & $56(54.9)$ \\
\hline covering PA & $76(74.5 \%)$ \\
\hline Change of antibiotics, $\mathrm{n}(\%)$ & $45(44.1 \%)$ \\
\hline Clinical diagnosis of VAP & $68(66.7 \%)$ \\
\hline
\end{tabular}

*: duration of mechanical ventilation before suspected VAP, ${ }^{* *}$ CPIS, Clinical pulmonary infection score.

\section{Table 2. Primers used for multiple cross displacement amplification in this study.}




\begin{tabular}{|l|l|l|}
\hline Primers & Sequences $\left(\right.$ ( $^{\prime}$-3 $^{\prime}$ ) & Length \\
\hline CP1 & GCCGAATTTCAGCATTTCCATCATG-CCTGAACTGACGGTCGCC & $43 \mathrm{mer}$ \\
\hline CP2 & CGATGCTTCCGGTGAAGGTGC-AACGGCACCGCTGTTG & $37 \mathrm{mer}$ \\
\hline F1 & GCCTTCCTGGTCCCCTTA & $18 \mathrm{nt}$ \\
\hline F2 & CGGCTTCGTCGCTCAG & $16 \mathrm{nt}$ \\
\hline C1 & GCCGAATTTCAGCATTTCCATCATG & $25 \mathrm{nt}$ \\
\hline C2 & CGATGCTTCCGGTGAAGGTGC & $21 \mathrm{nt}$ \\
\hline D1 & ACTCCTAATGAACCCCAGT & $19 \mathrm{nt}$ \\
\hline D2 & ACCCGAACGCAGGCTATG & $18 \mathrm{nt}$ \\
\hline R1 & CAGAGCCAGCGCAGCA & $16 \mathrm{nt}$ \\
\hline R2 & GGCTGTGGCTGTGGGT & $16 \mathrm{nt}$ \\
\hline P1 & CCTGAACTGACGGTCGCC & $18 \mathrm{nt}$ \\
\hline P2 & AACGGCACCGCTGTTG & $16 \mathrm{nt}$ \\
\hline
\end{tabular}

Table3. List of bacterial strains

A total of 77 bacterial strains, which included 17 PA and 60 non-PA strains were identified by MALDI-TOF (microflex LT/SH, Bruker corporation, Karlsruhe, Germany) by the clinical microorganism laboratory of the Third Hospital of Xiamen.

\begin{tabular}{|l|l|l|l|}
\hline \multicolumn{1}{|c|}{ Bacteria } & strains & \multicolumn{1}{|c|}{ Bacteria } & Strains \\
\hline Pseudomonas. aeruginosa & 17 & Streplococcus agalactiae & 5 \\
\hline Escherichia coli & 5 & Enterococcus faecalis & 5 \\
\hline Staphylococcus. aureus & 5 & Salmonella typhimurium & 5 \\
\hline Acinetobacter baumannii & 5 & Klebsiella. pneumoniae & 5 \\
\hline Staphylococcus epidermidis & 5 & Enterobacter cloacae & 5 \\
\hline Staphylococcus capitis & 5 & Stenotrophomonas maltophilia & 5 \\
\hline Streptococcus pyogenes & 5 & & \\
\hline
\end{tabular}

\section{Figures}




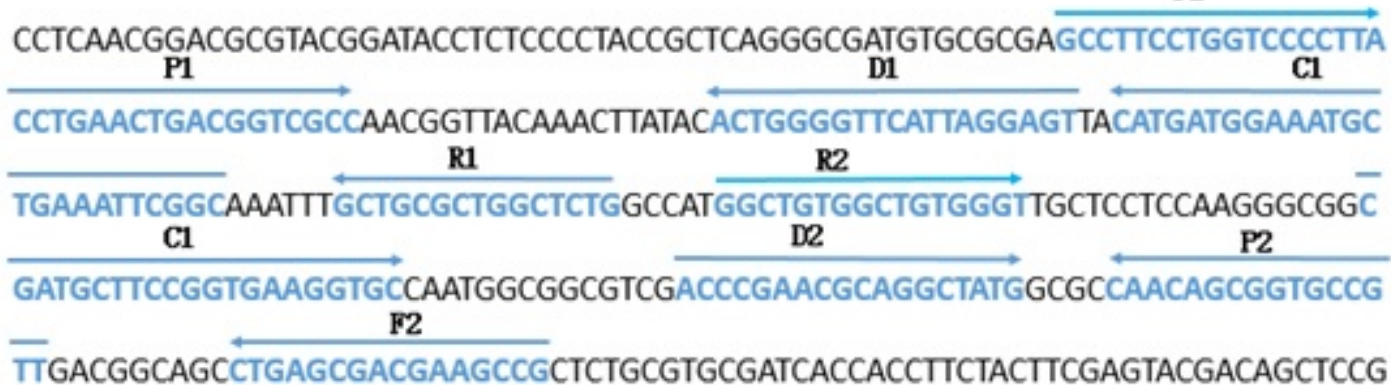

\section{Figure 1}

Schematic depiction of the primer sequences and positions for MCDA. The location and nucleotide sequence of the P. aeruginosa oprL gene that assisted in designing MCDA primers. The primer site sequences are underlined. Right and left arrows indicate sense and complementary sequences that were used in the assay. 


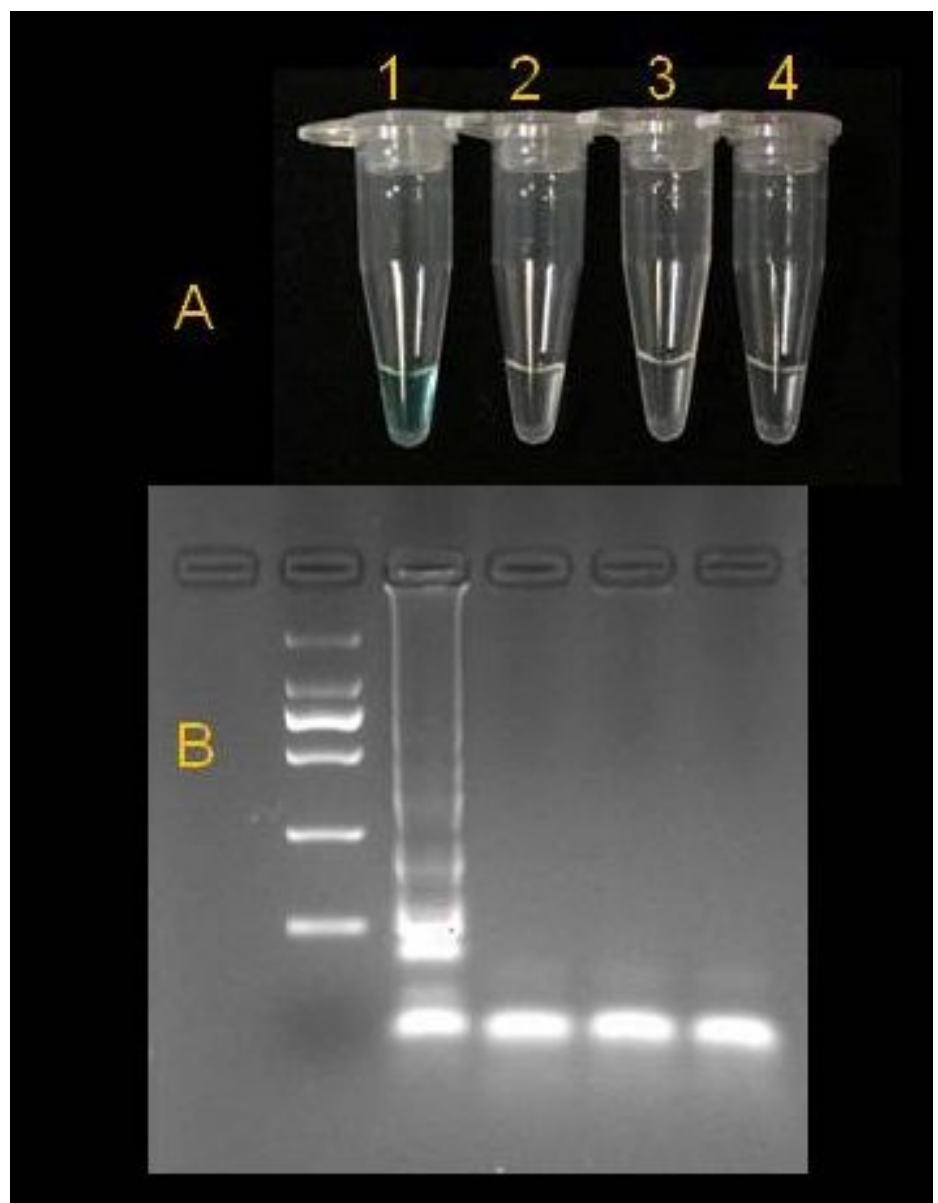

\section{Figure 2}

Confirmation and detection of products. (A) The color change seen in MCDA tubes: tube 1 is the positive amplification of P. aeruginosa, the green color was observed directly; tubes 2 and 3 are the negative amplifications of $\mathrm{S}$. aureus and $\mathrm{K}$. pneumoniae respectively; tube 4 is the negative amplification of the control (no DNA);tubes 2, 3 and 4 remained colorless. (B) 2.5\% agarose gel electrophoresis applied to MCDA; lane 0:DL 100-bp DNA marker; lane 1: positive MCDA products of P. aeruginosa; lane 2 and 3: negative products of $S$. aureus and K. pneumoniae respectively; and lane 4, negative control (no DNA). 
Block A OHo Connection / $\left.59.0^{\circ} \mathrm{C}\right): U(59)$

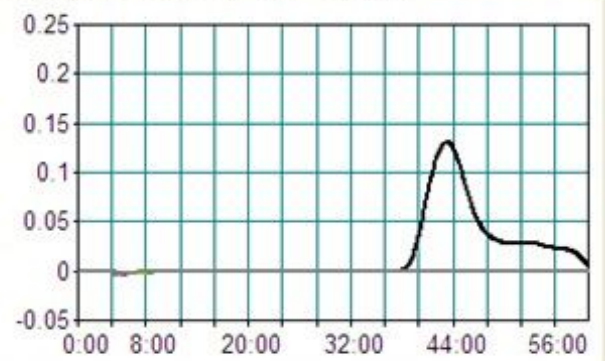

Setting Display $\int$ Result $\odot$ Judenent $\Gamma$ Anplificati

Block D owo Connection / 62. $\left.0^{\circ} \mathrm{C}\right): \mathrm{U}(62)$

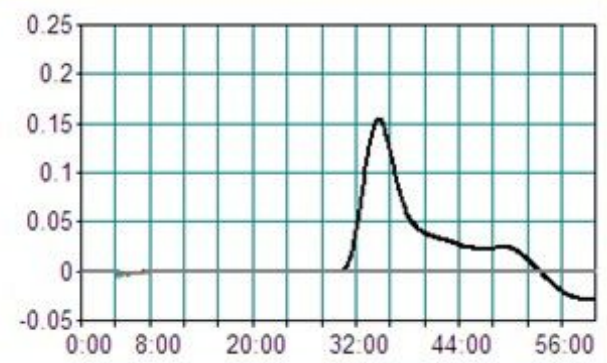

Setting Display| $\mathrm{C}$ Result $($ Judgment $C$ Amplificati

Block C ONo Connection / $\left.65.0^{\circ} \mathrm{C}\right): \mathrm{U}(65)$

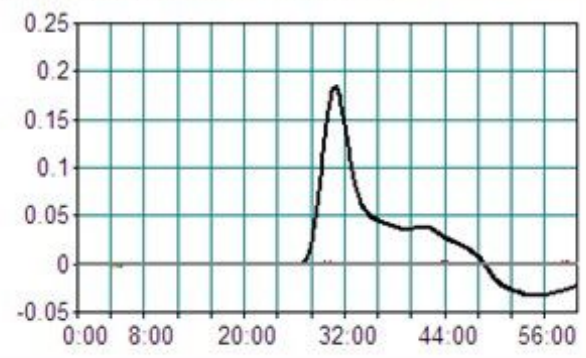

Block B (to Connection / $\left.60.0^{\circ} \mathrm{C}\right): \mathrm{U}(60)$

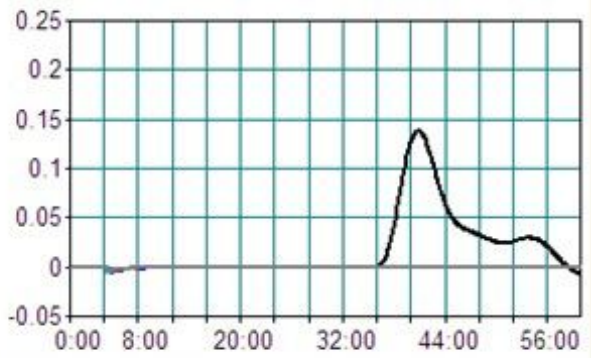

Setting Display $C$ Result $C$ Judgnent $C$ Amplificat

Block AOH。Connection / $\left.63.0^{\circ} \mathrm{C}\right): \cup(B 3)$

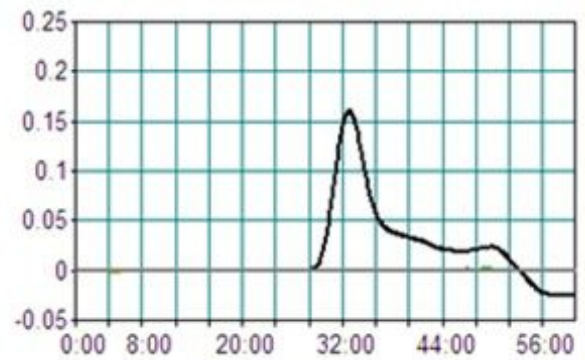

Setting Display $\int$ Result 0 Judement $C$ Anplificati

Block D Oso Connection / $\left.66.0^{\circ} \mathrm{C}\right): U(66)$

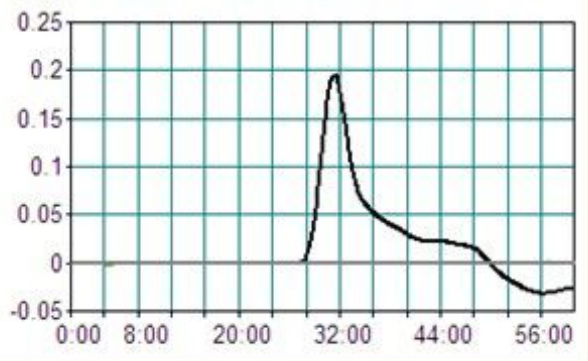

Block C $0 N_{0}$ Connection / $\left.61.0^{\circ} \mathrm{C}\right): \mathrm{U}(61)$

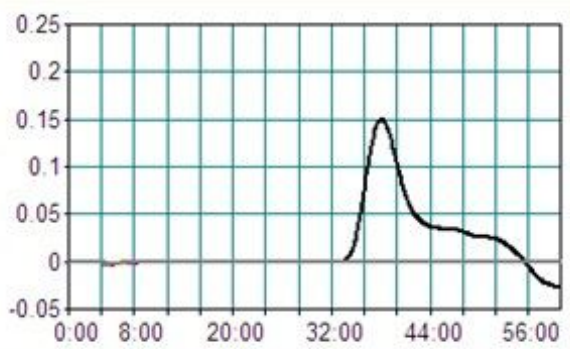

Setting Display $\bigcirc$ Result $C$ Judgent $C$ Amplificati

Block B 0i。 Connection / $\left.84.0^{\circ} \mathrm{C}\right): \mathrm{U}(64)$

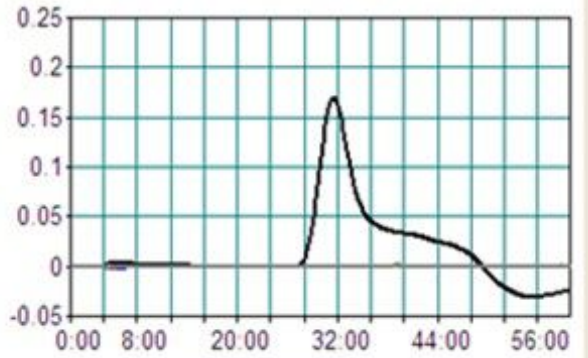

Setting $\mid$ Display $\mid \subset$ Result $C$ Judgnent $\Gamma$ Amplificati Block A Q $\mathbb{N}_{0}$ Connection $\left./ 67.0^{\circ} \mathrm{C}\right): \cup(67)$

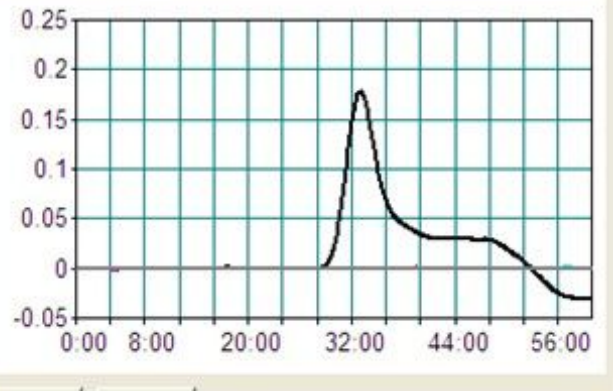

\section{Figure 3}

Optimal reaction temperature for the PA-MCDA primer assay. MCDA reactions when detecting the $\mathrm{P}$. aeruginosa gene were monitored by real-time measurement of turbidity. A turbidity of $>0.1$ was considered positive. Nine kinetic graphs were obtained at various temperatures $(59-67 \circ \mathrm{C}$, at $1 \circ \mathrm{C}$ intervals) with $\mathrm{P}$. aeruginosa DNA at a concentration of $1 \mathrm{ng}$ per tube. The graphs showed that $65^{\circ} \mathrm{C}$ was an optimal temperature for amplification. 


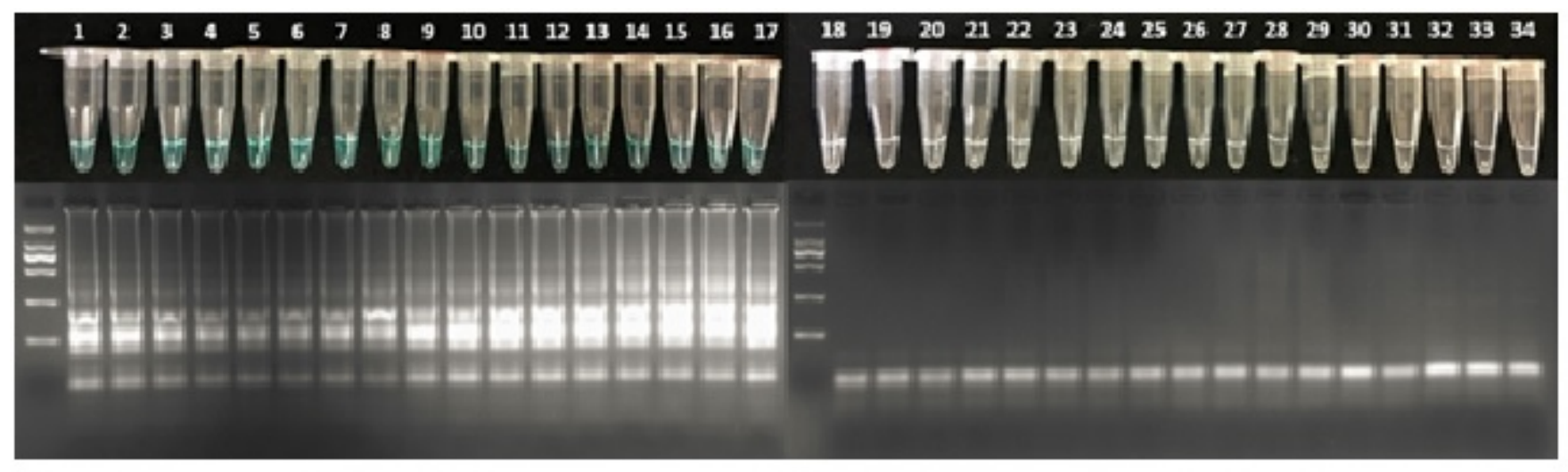

\section{Figure 4}

Specificity for P. aeruginosa detection by MCDA assays. Of all 77 pure genomic templates, only the genomic DNAs from the P. aeruginosa strains generated positive results. The color shift in the PA-MCDA tubes (tubes 1-17) was directly observed as a green color. A grey color was seen in tubes 18-34, in which 18-21 were E.coli. Tubes 22-23 were S. aureus, of which, tubes 24-25 were A. baumannii, and tubes 26-34 were respectively S. epidermidis, S. capitis, Streptococcus pyogenes, S. agalactiae, E. faecalis,S. typhimurium, K. pneumoniae, E. cloacae, and S. maltophilia. A 2\% agarose gel electrophoresis assay was applied to detect P. aeruginosa MCDA; lane 0, DL 100-bp DNA marker; lanes 1-17 were positive MCDA 
products that corresponded to P. aeruginosa tubes 1-17; and lanes 18-34 were negative and corresponded to tube 18-34 respectively.
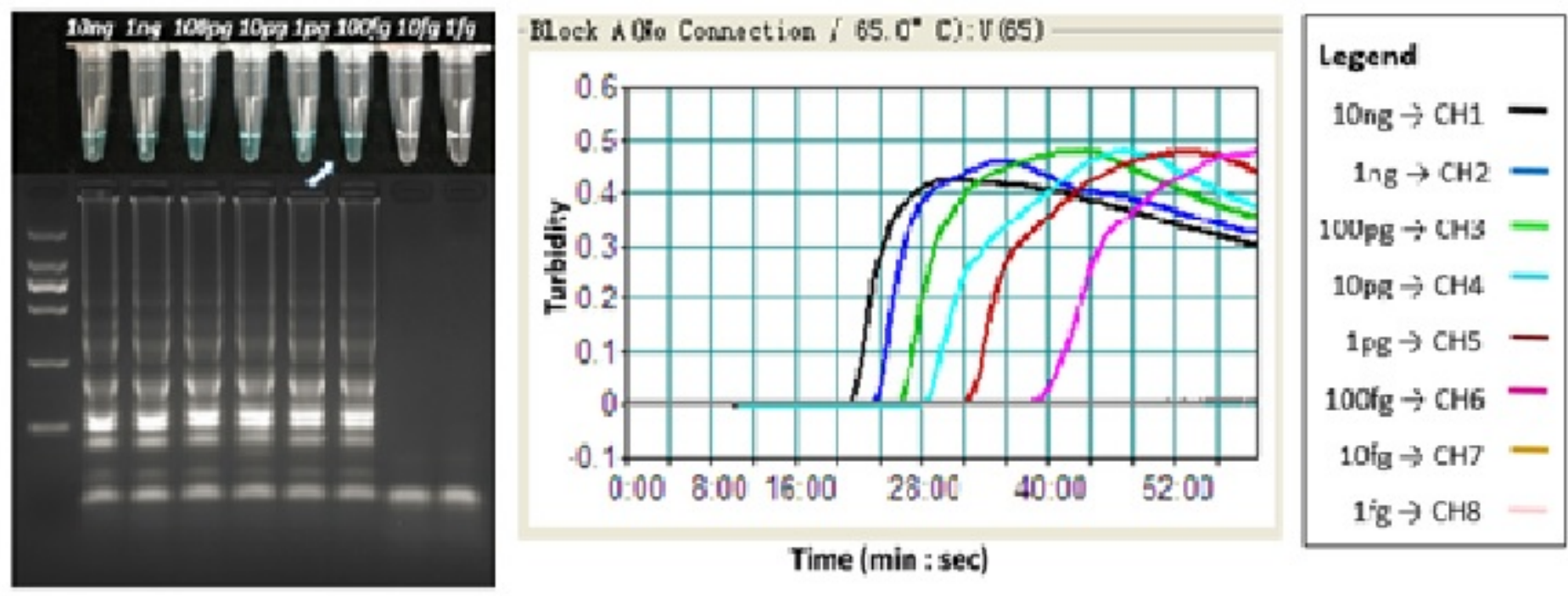

Time (min : sec)

\section{Figure 5}

Sensitivity of the MCDA assays using serially diluted P. aeruginosa genomic DNA. (A) P. aeruginosa genomic DNA was serially diluted to $10 \mathrm{ng}, 1 \mathrm{ng}, 100 \mathrm{pg}, 10 \mathrm{pg}, 1 \mathrm{pg}, 100 \mathrm{fg}, 10 \mathrm{fg}$ and $1 \mathrm{fg}$ per microliter. When the dilution was more than $100 \mathrm{fg} / \mathrm{uL}$, the green color by MG and the laddering P. aeruginosattern by agarose gel electrophoresis were directly observed. The LoD of the PA MCDA assay was as low as $100 \mathrm{fg}$ 
per microliter (white arrow). (B) Real-time turbidity was applied to analyze the amplification products. Genomic DNA levels $>100 \mathrm{fg}$ per reaction produced positive reactions.

\section{Supplementary Files}

This is a list of supplementary files associated with this preprint. Click to download.

- Additionalfiles.pdf 